\section{Public Health Genomics}

Public Health Genomics 2010;13:276-283

DOI: 10.1159/000242199
Received: January 5, 2009

Accepted after revision: June 3, 2009

Published online: September 23, 2009

\title{
Views on Personalized Medicine: Do the Attitudes of African American and White Prescription Drug Consumers Differ?
}

\author{
M. De Marco \\ Cecil G. Sheps Center for Health Services Research, University of North Carolina, Chapel Hill, N.C., USA
}

\author{
Key Words \\ African Americans - Focus groups - Genetic testing • \\ Personalized medicine $\cdot$ Race-based prescribing
}

\begin{abstract}
Aims: Although recent advances in pharmacogenomics are making possible the use of genetic testing to determine the best medication for patients, little is known about how patients view such procedures. The aims for this study that were developed collaboratively as part of a community-academic partnership are: (1) What are the attitudes and perceptions of prescription drug consumers concerning personalized medicine and genetic testing for drug compatibility and how do they differ between African American and white patients? (2) What are the attitudes and perceptions of patients concerning race-based prescribing and how do they differ between African American and white patients? Methods: We conducted 6 focus groups, 2 with white participants and 4 with African American participants. Focus groups were audio-recorded, transcribed, and analyzed to ascertain common themes. Results: Our results suggest that personalized medicine and genetic testing, though not well understood by lay persons, were considered positive advances in medicine. However, participants also voiced concerns about these advances that differed by race. Conclusion: This study points to the need to include perspectives of at-risk communities as we move toward wider use of this technology.
\end{abstract}

Copyright $\odot 2009$ S. Karger AG, Basel

\section{KARGER}

Fax +4161306 1234

E-Mail karger@karger.ch

www.karger.com
(C) 2009 S. Karger AG, Basel

Accessible online at:

www.karger.com/phg
Recent advances in pharmacogenomics have heralded the current era of personalized medicine - using genetic testing to select the best medication for patients. This practice has the potential to reduce the trial-and-error method of prescribing and side effects [1]. However, the science and clinical application of genetic testing for personalized medicine have not yet caught up to the vision. Due to the gap between scientific advances and practical application the current trend of marketing specific drugs to different racial/ethnic groups has arisen. As a result, in the absence of ubiquitously available pre-prescription genetic testing and genetically tailored therapies, physicians may use race as a proxy for testing before treating. Such decisions are likely due to a commonly held belief that genetics and race are linked and a provider's desire to personalize treatment choices. As health professionals continue down the road of personalized medicine, it will be important to understand the acceptance of these practices among diverse patients.

In its report on the potential of pharmacogenomics the Advisory Committee on Genetics, Health, and Society to the Secretary of the U.S. Department of Health and Human Services calls for the engagement of the lay community on issues pertaining to the benefits, risks, and limitations of genetic technology [2]. These issues include perceptions of and receptiveness to pharmacogenomics and willingness to use the technology and participate in studies. In past research lay health consumers have expressed concerns that the cost and availability of new 
medications may result in widening health inequalities [3] and that genetic testing might lead to breaches of confidentiality, misuse of positive test results, and discrimination by insurers [4]. In addition marketing messages linking race, genes, and heart disease that specified blacks or whites as the subject of the message led to higher levels of racist attitudes such as belief in a genetic basis for racism [5].

While some research on genetic technology has examined racial differences and included community members' input into the study [6], we have found no studies that have gone as far as to engage the lay community in posing the research questions or designing the research study. The present study fills that gap by being part of a larger project that employs community-based participatory research (CBPR) strategies. In addition to its other benefits, community participation has been demonstrated to be an important component in overcoming mistrust of health researchers by marginalized populations because individuals directly affected by the research topic are involved in the research [7-9]. Moreover, community engaged research is more likely to produce results that are trusted by those affected and lead to meaningful community change. The research questions for this study that were developed collaboratively as part of a communityacademic partnership are: (1) What are the attitudes and perceptions of health care consumers concerning personalized medicine and genetic testing for drug compatibility and how do they differ between African American (AA) and white patients? (2) What are the attitudes and perceptions of patients concerning race-based prescribing and how do they differ between AA and white patients?

\section{Methods}

Research Collaboration Background

In 2003 researchers from the University of North Carolina, Chapel Hill (UNC) Program on Ethnicity, Culture, and Health Outcomes came together with the leadership of The Partnership Project in collaboration to reduce health disparities. The resulting Health Disparities Collaborative was formed by community leaders, public health researchers, clergy, and healthcare professionals following the 9 principles of CBPR [10]. CBPR is an orientation to research that combines methods of inquiry with community capacity-building strategies in an effort to produce social change to improve health [11]. The CBPR principles that we follow include negotiating a working process that includes team-building, power-sharing in decision making, equal partnerships, and shared learning. The impetus for incorporating CBPR strategies is to address the disconnect between knowledge gained from conventional research and the translation of new knowledge into actions that improve the health of marginalized populations. The forma- tion of an equitable research partnership with members of such communities allows community members to have ownership of a project, collaborate on intervention implementation, and trust the findings.

In 2007, as part of the UNC Clinical and Translational Science Award effort, researchers from UNC came to the Collaborative and asked members to describe the health issues of concern to them. One of these issues was the respectful prescribing of medications and whether prescribing behaviors differed depending on a patient's race. Researchers and Collaborative members developed a workgroup that jointly developed the research questions and study design and conducted the study.

\section{Sampling Strategy and Recruitment}

Study participants were recruited from 2 clinics and a family practice center at a large public medical center in a central North Carolina city. These clinics were selected to ensure a diverse demographic mix of study participants. To be eligible, participants had to be between 25 and 70 years and be consistently on a medication prescribed by their regular provider. Preference was given to those who took medications for chronic conditions. Clinic staff approached patients when they came in for an appointment and told them about the purpose of the study and the incentive for participation (a \$35 gift card). If a patient was interested, his/her contact information was relayed to the study coordinator. The study coordinator telephoned each participant, screened for eligibility, extended an invitation to participate in a focus group, and gave information on the time, date, and location of the focus group. A signed informed consent document was obtained from each participant prior to the focus group.

\section{Data Collection}

Focus group interviews, stratified by race, were conducted to ensure thematic saturation. A trained facilitator, matched by race, moderated each group. Between December 2007 and May 2008, 6 focus groups were held, 2 with white and 4 with AA participants. Focus groups lasted approximately 90 minutes. Data were collected on sociodemographics, health insurance status, and prescription drug coverage of the participants. Audio recordings were transcribed and reviewed for accuracy. The study was approved by the medical center institutional review board.

The moderators' guide consisted of primarily open-ended questions developed by the community-academic working group. The guide begins with questions about considerations medical providers should be aware of when prescribing medication. Participants were then asked whether medications should be prescribed based on gender or race, how prescribing medication based on race might affect racism, and views on personalized medicine. The definition of personalized medicine provided to the participants was: 'Personalized medicine is the management of a patient's disease by understanding how an individual's genes affect how his/her body responds to medications. Science is trying to identify and record as many genetic variations as possible. Scientists can then match a person's gene profile with the likely response to a medication. Your unique genetic profile can help your doctor personalize your treatment.' 'For example, a 40-year old African American woman who has a high chance of developing breast cancer based upon a defect in a certain gene that she carries can work with her doctor to determine if she is among a percentage of those for whom a particular drug is likely to work.' 
Table 1. Focus group demographics

\begin{tabular}{llrllllll}
\hline Group & Race & $\mathrm{n}$ & $\begin{array}{l}\text { Age } \\
\text { range }\end{array}$ & Female & Married & $\begin{array}{l}\text { High school diplo- } \\
\text { ma or less and/or } \\
\text { technical school }\end{array}$ & $\begin{array}{l}\text { No health } \\
\text { insurance }\end{array}$ & $\begin{array}{l}\text { No prescription } \\
\text { insurance }\end{array}$ \\
\hline 1 & AA & 11 & $27-61$ & $7(63.6 \%)$ & $4(36.4 \%)$ & $8(72.7 \%)$ & $7(63.6 \%)$ & $9(81.8 \%)$ \\
2 & white & 9 & $38-63$ & $7(77.7 \%)$ & $6(66.7 \%)$ & $5(55.6 \%)$ & $1(11.1 \%)$ & $3(33.3 \%)$ \\
3 & AA & 8 & $41-70$ & $6(75.0 \%)$ & $4(50.0 \%)$ & $8(100 \%)$ & $1(12.5 \%)$ & $2(25.0 \%)$ \\
4 & white & 5 & $54-64$ & $3(60.0 \%)$ & $5(100 \%)$ & $5(100 \%)$ & $2(40.0 \%)$ & $2(40.0 \%)$ \\
5 & AA & 7 & $35-53$ & $6(85.7 \%)$ & 0 & $6(85.7 \%)$ & 0 & $4(57.1 \%)$ \\
6 & AA & 8 & $34-65$ & $8(100 \%)$ & $1(12.5 \%)$ & $6(75.0 \%)$ & 0 & $1(12.5 \%)$ \\
\hline Total & & 48 & $27-70$ & $37(77.1 \%)$ & $20(41.7 \%)$ & $38(79.2 \%)$ & $11(22.9 \%)$ & $21(43.8 \%)$ \\
\hline
\end{tabular}

${ }^{a}$ Many participants were on Medicaid or Medicare with only minimal prescription drug coverage.

Other topics covered included views on genetic testing for drug compatibility, reasons for non-adherence to prescription medication, and experiences with pharmacists.

Analytic Strategy

The workgroup conducted an initial review of the transcripts to look for new or emergent themes. Next, potential themes and subthemes were developed based on the literature review, research questions, and focus group questions. Workgroup members met to discuss initial impressions. A codebook was created with definitions for themes and subthemes and rules for coding the text data. One workgroup member coded all 6 transcripts, using ATLAS.ti (ATLAS.ti, Berlin, Germany), based on discussion by the full group.

The number of text pieces sorted into each code was reviewed to ascertain relative magnitude and to look for patterns with the rule that patterns must be supported by at least 3 occurrences of the same idea [12]. Themes were examined with the focus group being the unit of analysis. Group members met to interpret the results.

\section{Results}

A total of 48 people participated in the 6 focus groups (34 AA [70.83\%], 14 white [29.17\%]). Of the 6 groups, 4 were conducted with predominately low SES (socioeconomic status) AAs, 1 with low SES whites, and 1 with higher SES whites. The demographic and insurance characteristics of each focus group are shown in table 1. Characteristics of the participants include that $79.41 \%$ of the AA participants were female and $26.47 \%$ were married and $71.43 \%$ of the white participants were female and $78.57 \%$ were married.

Focus group participants were asked their opinions of the practices of personalized medicine, race-based pre- scribing, and genetic testing. These opinions and the differences between AA and white focus groups are described below. Illustrative quotes are shown in table 2 .

\section{Attitudes towards Personalized Medicine}

All focus groups held generally positive views of personalized medicine. However, participants in the AA focus groups spent a greater amount of time discussing positive views than did the white focus groups. These positive aspects included fewer side effects and less trialand-error when prescribing. In contrast, white focus groups concentrated more on the view that while personalized medicine is an exciting prospect it will take time before the full potential is realized.

AA focus groups were concerned about the cost of personalized medicine and what that would mean for those with a limited ability to pay because they lack insurance that will cover it or do not have the money to pay for the procedure out-of-pocket. Finally, there was much agreement in one AA focus group that even with personalized medicine medical mistrust would still be an issue. These themes were absent from the white focus groups.

\section{Attitudes towards Genetic Testing}

Participants had much less to say about genetic testing than personalized medicine, in part due to limited knowledge about genetic testing and the need for pre-prescription testing. In fact, participants in both white focus groups and 1 of the AA focus groups expressed a desire to know more about the practice before they would participate. Still, similar to personalized medicine, both AA and white groups held similarly favorable views of genetic testing as a way to find the best medication. Both groups 
Table 2. Thematic quotations on positive and negative aspects of personalized medicine, race-based prescribing, and genetic testing from African American (AA) and white focus groups

AA White

Personalized medicine

Positive 'Like you say with joint problems, stomach upset, the medicine may be able to more synthesize with your system so that you're not experiencing all of these different emotional ups and downs, um, sickness, diarrhea, constipation ... all the other symptoms, all the other side effects.' (FG5)

'And, it's not as time consuming as it is if you keep going back and forth to the doctor trying to figure out what's gonna work.' (FG6)

Negative 'I think our knowledge base is so minimal on this right now too. It's gonna be a very long time til this is gonna be any kind of trustworthy even component of the whole prescription process. I mean, you think about medication interactions. When you're testing efficacy and safety of drugs and, and doing it on the basis of genetic profile, you can't test every combination of all the thousands of drugs that are out there.' (FG2) 'M: Can you see any disadvantages?

R: To me just the cost like she said.

R: I think it gonna depend on, again, public or private insurance.

M: If insurance covers it?

R: Mmm, insurance, yeah.' (FG5)

'I think there would still be a trust issue though with the medical community. I think that's the, that's the problem that we get into when we start talking about personalized medicine.' (FG5)

Genetic testing

Positive 'Because that way they'll know that will work for me and what won't work for me, and ... it won't take me through the, you know, uh, thing of getting this prescription, trying this, you done spent your money on this, this doesn't work. You don't get a refund.' (FG1)

'It will save you some other conditions too ... Save you going through the, the sickness or sometimes you'll be sick for 2 weeks while taking a pill.' (FG5)

Negative 'I think that's a win-win for everybody, but probably so cost prohibitive that couldn't even be done in the near future, on any regular basis. But, sounds good.' (FG4)

'But, even if ... you have private healthcare insurance ... and the doctor wants to do this genetic testing to see whether that works best for you or not. The health insurance company may decide that it's not necessary, and it's too expensive, and they want to do the old trial-and-error way.' (FG2)

'R1: Your insurance company gets a hold of it [genetic information], well, what's gonna happen to your premiums?

R3: Well, they're gonna drop you, or, they're, or ...

R3: Your premiums are gonna go sky high.

R1: Or your perspective employer. They don't want to hire you if they know your gonna get sick.' (FG2)

'I would be interested in, in genetic testing. But, it's, it's something you don't enter into lightly. I mean I'm not sure how I would feel if somebody tells me you have the BRCA gene or whatever it is for breast cancer. I don't know right now if I want to know that.' (FG2)

Race-based prescribing

Positive 'Some medications have been researched to say they fit one ethnicity better than another.' (FG3)

'I actually think it's a good idea because genetically the races are different, I mean look, you just have to look at the preponderance of African Americans with hypertension.' (FG2)

'So, we're gonna tell a whole group of people, "I'm sorry, you gotta take this medication because this is socially acceptable"?' (FG4)

Negative 'Because so much has been, been given to ... us in particularly our, our community, black people, that ... there's a big factor of whether or not they're giving us stuff to help us or to hurt us.' (FG5)

'The ones that's on Medicare or Medicaid or no insurance at all they should be able to get the same thing, [as] those that can afford to get their medicine. Because see ... when a doctor takes an oath ... to help that person no matter, no matter the race, how much money you got, or anything, they're not supposed to look at those things.' (FG6)

'Because that's racist to say like she white, I'm black, we both got diabetes but her, her diabetes is a lot worse than mine. Uh, but, but he gonna give me the ... stuff that's gonna hurt me, but gonna give her the stuff that's gonna help bring down her, uh, sugar level. Nope. That ain't right.' (FG6) 'I think they should treat them just like they treat me, or her, or any of us.' (FG4)

$+$

$+$

$+$ 
saw genetic testing as a promising practice for reducing the risks in the current method of prescribing. Similar to the views of personalized medicine, participants believed that genetic testing would decrease side effects and reduce the trial-and-error nature of prescribing, thus saving money.

White focus group participants talked to a greater extent about genetic testing than did AA groups. The white focus groups held positive views on genetic testing but expressed concern that the practice would be too expensive to be accessible. White focus group members also agreed that insurance companies might not pay for a procedure to determine the best medication because of high costs. In addition, white groups, confounding genetic testing to determine drug compatibility and genetic testing to assess disease vulnerability, worried about possible insurance and employment discrimination due to discovery of a genetic predisposition for a specific disease or from simply being tested. White groups also expressed concerns about receiving clinically important information. There was agreement in the white groups that they would not want to know if they had a genetic predisposition for some diseases and that genetic testing should be entered into with a degree of caution.

As opposed to the discussion in the white groups, there was only 1 mention of a negative aspect of genetic testing in any of the AA focus groups. This participant believed that she was already taking too many medications and genetic testing would just increase the number she had to take.

\section{Attitudes towards Race-Based Prescribing}

White and AA focus groups held some similar and some disparate views of race-based prescribing. There was minimal discussion in the AA focus groups regarding positive aspects of race-based prescribing. One AA participant had heard of medications that were race-specific, perhaps referring to BiDil, the first medication approved specifically for AAs [13]. One participant in an AA focus group thought that prescribing medications based on race made sense, but there was no agreement with this in the focus group. The majority of the discussion in AA focus groups around race-based prescribing revealed negative views, including strong endorsement of medical mistrust. AA focus group participants strongly endorsed the sentiment that race-based prescribing was racist and AAs might receive inferior medications because of this practice.

Contrary to what was seen in the AA focus groups, white focus groups did hold some positive views of race- based prescribing. White focus groups reasoned that because certain groups of people are prone to particular illnesses race-based prescribing may be a good option. Other white focus groups cited concerns such as people with lighter skin being more susceptible to skin cancer and Asian individuals having reactions to alcohol as supportive of race-based therapies. Still, white focus group participants disagreed about whether medications should be prescribed based on race. Some white focus group members were worried about issues of equity. However, one white participant voiced, and others agreed, that in an effort to treat everyone the same, we might miss out on more effective treatment options.

White focus groups worried that race-based prescribing might cause insurance premiums to rise for certain races if they were found to be more susceptible to certain diseases. They also worried that individuals with public insurance or none at all would receive inferior care. There was strong agreement in one white group regarding this idea. White participants also noted that while race may be useful for tailoring medications the practice could perpetuate discrimination.

Of note, both AA and white focus groups conflated race with socioeconomic class when discussing their attitudes about race-based prescribing, although for AA focus groups this was more pronounced. Two AA focus groups expressed concerns about receiving the best medications regardless of insurance status and stated that race should not be a factor.

\section{Returning Results to the Community}

The workgroup felt the results should be shared with the community to provoke transformative action on personalized medicine and the issues of the larger study. This sharing of results to create change is a key aspect of CBPR [11]. Toward that end, a community forum was held to share findings and provide study participants with information to address their concerns and some misunderstandings about prescribing practices and personalized medicine. Community members of the workgroup took responsibility for preparing and presenting the majority of the information during the forum. Focus group participants, many of whom had expressed reticence toward participation in research or genetic testing to determine drug compatibility, were given the opportunity to learn more about participation in a clinical trial and its benefits. Participants were given information on the importance of knowing their family medical history and how to collect that information as a way of receiving more appropriate care until genetic testing is widely available. 
In addition to the forum, study findings were carried in the regional newspaper and shared through the quarterly in-house publication for health care providers and staff from the health care system where the participants received their care. Next steps in addressing the findings include providing training to physicians within the local health care system using the Partnership Project's 'Undoing Racism' curriculum as a basis for better communication with patients. Another effort under consideration will be to conduct roundtable discussions with focus group participants to identify workable solutions that improve patient-provider communication around these issues.

\section{Discussion}

In this study, we examined patients' attitudes about personalized medicine, genetic testing, and race-based prescribing and whether they differed between white and African American participants. Our results suggest that personalized medicine and genetic testing, though not well understood by lay persons, were considered positive advances in medicine. However, participants also voiced a range of concerns. For example, participants felt that, while promising, the use of genetic testing to personalize medicine might be too expensive to be accessible to the general public. We also found that medical mistrust by marginalized populations, as discussed in particular in the AA focus groups, may affect the acceptability of personalized medicine when it becomes widely available. Further, our results contribute to the field by demonstrating that lay persons are suspicious of the practice of using race as a method for tailoring medications, a finding more pronounced in AA participants than whites and made particularly relevant by the BiDil study [13]. Still, African Americans viewed personalized medicine and genetic testing as positive developments that could reduce the trial-and-error nature of prescribing and the possibility of side effects. It is encouraging that African Americans hold these views because it suggests that they may accept this new technology, which is particularly important in light of previous research $[14,15]$ indicating that African Americans may potentially derive greater benefit from such technology than whites.

Beyond the findings themselves, the importance of the methods utilized cannot be overlooked. The CBPR framework allowed for community involvement in a rich discussion of complex issues that identified barriers and perceptions that an investigator-centric approach could not have developed. This is one of the few studies con-

Attitudes of African Americans and

Whites on Personalized Medicine cerning genetics and genetic research that has actively engaged community members in the research process from development of research questions to study design and data analysis. Another study engaged the community by asking lay persons to provide feedback on consent forms for use when collecting blood samples [16]. However, community members were not involved in the study design, data collection, analysis, and dissemination of results as in the present study.

The current status of personalized medicine and racebased prescribing has been well documented in the scientific literature $[17,18]$. However, this academic-community partnership provides a process not only to identify how lay persons feel about complex genetic topics but also provides a vehicle for addressing the issues that arise. In addition, by involving lay persons as equal partners in research, the community takes ownership for the findings and their dissemination. The engagement of community in conducting research, disseminating findings, and educating the public could be particularly powerful in reducing barriers to the use of personalized medicine by making complex topics relevant and understandable and helping researchers recognize the concerns and needs of communities.

Overall, study participants, regardless of race, deemed personalized medicine and genetic testing to be beneficial; however, many of them did not have a clear understanding of what these practices entail. Clearly as preprescription genetic testing and personalized medicine become more widespread, improving lay literacy on the terms and procedures involved will be critical to acceptance of research and clinical application. In particular, patients need to understand the purpose of genetic testing and how it can be used together with other clinical information to determine the best treatment. Health professionals will need to draw from many disciplines such as psychology, anthropology, and advertising to create social marketing campaigns that address the numerous barriers to acceptance and utilization.

Even in the face of overall positive views of personalized medicine, some participants were wary of participating in any sort of medical testing, believing that they might be exploited or the privacy of test results be compromised. One way to address this concern is to provide patients with information about the Genetic Information Nondiscrimination Act (GINA), legislation signed into law in 2008 to protect patients from discrimination by their health insurers and employers based on their genetic information. An approach similar to the dissemination of information during health care visits on the Health Insurance Portability 
and Accountability Act (HIPAA), which set national standards for the protection of the privacy of personal health information, could be undertaken. Dissemination of information on GINA may address concerns about the leakage of test results, but worry about potential exploitation may still exist. As seen in this study, community involvement can be vital to addressing these concerns. Academiccommunity partnerships can help address mistrust of the medical community by historically marginalized people through facilitated dialogue between members of these groups and the medical community. In addition, medical providers, public health professionals, and health researchers can address key misperceptions about genetic testing, for example patient concerns that genetic testing is an experiment which will not give direct benefit.

The results of this study can also be used to educate genetic scientists and medical providers about patients' attitudes concerning personalized medicine and genetic testing. If scientists developing genetic tests and targeted medications and medical providers prescribing them understand these misperceptions and reservations, the concerns can be addressed using appropriate marketing information and direct conversation with patients in the office setting.

The results of this study should be viewed in light of its limitations. One limitation is that 1 of the 2 white focus groups was held with higher SES participants, while all AA focus groups were held with predominantly low SES participants. Differences seen between the 2 racial groups may be attributable to class not race; however, the groups represent the demographic mix seen in the healthcare system and local community from which they were recruited. Also, focus groups are subject to the dynamics of the group, which may be dominated by a small number of voices. Future research may benefit by utilizing another method of data collection that allows anonymity, such as a survey, which may elicit divergent views that people may be uncomfortable voicing within a group. Last, participants confused genetic testing to assess disease vulnerability with testing to determine the most appropriate medication due to the complexity of these technologies, even though, to combat this, we were careful to probe for opinions to specific technologies. Future research may benefit from the provision of even more examples of the differences between these 2 technologies to anchor participant discussion.

When asked their opinions about personalized medicine, genetic testing, and race-based prescribing, African American participants appeared to be most concerned about the receipt of inferior medications and expressed general mistrust of the motives of the medical community while white participants were concerned about cost. Both groups were concerned about what these practices would mean in terms of equity, but African American participants were concerned about this for themselves while white participants were thinking of society at large. This difference is understandable in light of the historic exploitation perpetrated on the African American community [19]. Another difference was that fewer African Americans than whites in this sample had prescription drug coverage, which may explain the finding that African Americans were concerned that these new technologies would cost more than they could afford to pay outof-pocket while whites worried that the high cost meant that insurance companies would not cover medications prescribed via this method. Despite these misgivings, both African American and white participants believed that personalized medicine was a good idea, although one with which they were not yet familiar. As the state of the science of genetic testing for drug compatibility marches forward, we must not lose sight of the patients' perspective. Personalized medicine will not reach its potential without concerted and effective efforts to involve and educate at-risk communities.

\section{Acknowledgements}

This research was supported by grants M01RR00046 and UL1RR025747 from the National Center of Research Resources, National Institutes of Health and partially supported by a National Research Service Award Pre/Post-doctoral Traineeship from the Agency for Health Care Research and Quality sponsored by the Cecil G. Sheps Center for Health Services Research, University of North Carolina at Chapel Hill, Grant No. T32-HS-0003220 . The content is solely the responsibility of the authors and does not necessarily represent the official views of the National Center for Research Resources or the National Institutes of Health. The authors also wish to thank Carla Freeman and Gratia Wright for their skilled focus group moderation, Connie Blumenthal for her support in study design and instrument development, and all those who participated in this study for sharing their stories.

References

1 Smart A, Martin P, Parker M: Tailored medicine: whom will it fit? The ethics of patient and disease stratification. Bioethics 2004;18: 322-342.

2 Secretary's Advisory Committee on Genetics, Health, \& Society. Realizing the Potential of Pharmacogenomics: Opportunities and Challenges: 2008. Available at http://www4. od.nih.gov/oba/sacghs/reports/SACGHS PGx_report.pdf, accessed June 30, 2008. 
3 Almarsdottir A, Bjornsdottir I, Traulsen J: A lay prescription for tailor-made drugs - focus group reflections on pharmacogenetics. Health Policy 2005; 71:233-241.

4 Catz DS, Green NS, Tobin JN, Lloyd-Puryear MA, Kyler P, Umemoto A, Cernoch J, Brown $\mathrm{R}$, Wolman F: Attitudes about genetics in underserved, culturally diverse populations. Community Genet 2005;8:161-172.

5 Condit C, Parrot R, Bates B, Bevan J, Achter P: Exploration of the impact of messages about genes and race on lay attitudes. Clin Genet 2004;66:402-408.

6 Bevan JL, Lynch JA, Dubriwny TN, Harris TM, Achter PJ, Reeder AL, Condit CM: Informed lay preferences for delivery of racially varied pharmacogenomics. Genet Med 2003;5:393-399.

7 Corbie-Smith G: The continuing legacy of the Tuskegee Syphilis Study: considerations for clinical investigation. Am J Med Sci 1999; 317:5-8.

8 Gamble V: Under the shadow of Tuskegee: African Americans and health care. Am J Public Health 1997;87:1773-1778.

9 Thomas SB, Quinn SC: The Tuskegee Syphilis Study, 1932 to 1972: Implications for HIV education and AIDS risk education programs in the black community. Am J Public Health 1991;81:1498-1505.
10 Israel BA, Schulz AJ, Parker EA, Becker AB, Allen A, Guzman JR: Critical issues in developing and following community-based participatory research principles; in Minkler M, Wallerstein N (eds): Community-Based Participatory Research for Health. San Francisco, Jossey-Bass, 2003, pp 56-73.

11 Viswanathan M, Ammerman A, Eng E, Gartlehner G, Lohr KN, Griffith D, Rhodes, S, Samuel-Hodge C, Maty S, Lux L, Webb L, Sutton S, Swinson T, Jackman A, Whitener L: Community-Based Participatory Research: Assessing the Evidence. Report/ Technology Assessment No. 99 (Prepared by RTI-University of North Carolina Evidencebased Practice Center under Contract No. 290-02-0016). AHRQ Publication 04-E0222. Rockville, MD: Agency for Healthcare Research and Quality. July 2004. Available at http://www.ahrq.gov/downloads/pub/evidence/pdf/cbpr/cbpr.pdf.

12 Berg B: Qualitative Research Methods for the Social Sciences, ed 5. Boston, Pearson, 2004.

13 Taylor A, Cohn J, Worcel M, Franciosa J: The African-American Heart Failure Trial: background, rationale, and significance. J Natl Med Assoc 2002;94:762-769.

14 Liggett SB, Cresci S, Kelly RJ, Syed FM, Matkovich SJ, Hahn HS, Diwan A, Martini JS, Sparks L, Parekh RR, Spertus JA, Koch WJ, Kardia SL, Dorn GW 2nd: A GRK5 polymorphism that inhibits $\beta$-adrenergic receptor signaling is protective in heart failure. Nat Med 2008;14:510-517.
15 He W, Neil S, Kulkarni H, Wright E, Agan BK, Marconi VC, Dolan MJ, Weiss RA, Ahuja SK: Duffy antigen receptor for chemokines mediates trans-infection of HIV-1 from red blood cells to target cells and affects HIV-AIDS susceptibility. Cell Host Microbe 2008;4:52-62.

16 Rotimi C, Leppert M, Matsuda I, Zeng C, Zhang H, Adebamowo C, Ajayi I, Aniagwu T, Dixon M, Fukushima Y, Macer D, Marshall P, Nkwodimmah C, Peiffer A, Royal C, Suda E, Zhao H, Wang VO, McEwen J; International HapMap Consortium: Community engagement and informed consent in the International HapMap project. Community Genet 2007;10:186-198.

17 Bottinger E: Foundations, promises, and uncertainties of personalized medicine. Mt Sinai J Med 2007;74:15-21.

18 Lee C, Morton C: Structural genomic variation and personalized medicine. $\mathrm{N}$ Engl J Med 2008;358:740-741.

19 Washington H: Medical Apartheid: The Dark History of Medical Experimentation on Black Americans from Colonial Times to the Present. New York, Doubleday, 2006. 